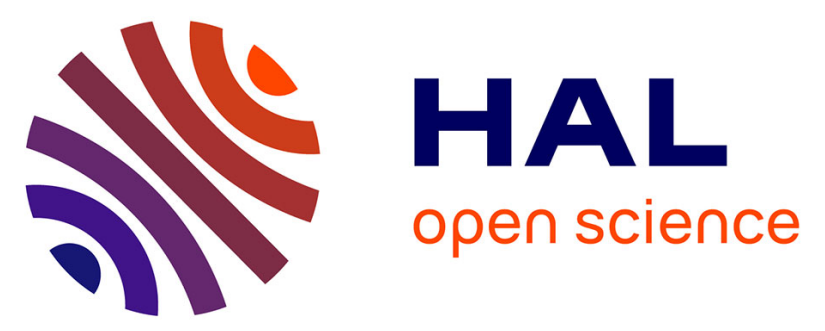

\title{
Clinical characteristics of urinary tract endometriosis: A one-year national series of 232 patients from 31 endometriosis expert centers (by the FRIENDS group)
}

Elise Froc, Gil Dubernard, Sofiane Bendifallah, Eric Hermouet, Chrystele Rubod-Dit-Guillet, Michel Canis, Sophie Warembourg, Francois Golfier, Arnaud Fauconnier, Horace Roman, et al.

\section{To cite this version:}

Elise Froc, Gil Dubernard, Sofiane Bendifallah, Eric Hermouet, Chrystele Rubod-Dit-Guillet, et al.. Clinical characteristics of urinary tract endometriosis: A one-year national series of 232 patients from 31 endometriosis expert centers (by the FRIENDS group). European Journal of Obstetrics \& Gynecology and Reproductive Biology, 2021, 264, pp.155-161. 10.1016/j.ejogrb.2021.06.018 . hal03482577

\section{HAL Id: hal-03482577 \\ https://hal.sorbonne-universite.fr/hal-03482577}

Submitted on 16 Dec 2021

HAL is a multi-disciplinary open access archive for the deposit and dissemination of scientific research documents, whether they are published or not. The documents may come from teaching and research institutions in France or abroad, or from public or private research centers.
L'archive ouverte pluridisciplinaire HAL, est destinée au dépôt et à la diffusion de documents scientifiques de niveau recherche, publiés ou non, émanant des établissements d'enseignement et de recherche français ou étrangers, des laboratoires publics ou privés. 
1 Clinical characteristics of urinary tract endometriosis: a one-year national

2 series of 232 patients from 31 endometriosis expert centers (by the

3 FRIENDS group).

4

5

6

7

8

9

\section{Authors}

\section{Elise FROC ${ }^{a}$, Gil DUBERNARD ${ }^{\mathrm{a}}$, Sofiane BENDIFALLAH ${ }^{\mathrm{b}}$, Eric HERMOUET ${ }^{\mathrm{c}}$, Chrystele} RUBOD-DIT-GUILLET ${ }^{\mathrm{d}}$, Michel CANIS ${ }^{\mathrm{e}}$, Sophie WAREMBOURG ${ }^{\mathrm{a}}$, Francois GOLFIER, Arnaud FAUCONNIER ${ }^{\mathrm{g}}$, Horace ROMAN ${ }^{\mathrm{h}}$, Charles-André PHILIP*a

\section{Affiliations:}

a Department of Gynaecologic and Oncologic Surgery and Obstetrics, Hôpital de la Croix Rousse, Hospices Civils de Lyon, Université Lyon 1, France. elise.froc@gmail.com, gil.dubernard@chu-lyon.fr, sophie.warembourg@chu-lyon.fr, charles-andre.philip@chulyon.fr

${ }^{\mathrm{b}}$ Department of Gynaecology and Obstetrics, Tenon University Hospital, Assistance Publique des Hôpitaux de Paris (AP-HP), Faculté de Médecine Sorbonne Université, Institut Universitaire de Cancérologie (IUC), France, sofiane.bendifallah@aphp.fr

${ }^{\mathrm{c}}$ Department of Gynaecologic Surgery and Obstetrics, Clinique Sud Vendée, Fontenay le Compte, France, drerichermouet44@gmail.com

dGynaecology Surgery Department, CHU Lille, F-59000, Lille, France; Lille University, Faculty of Medicine, F-59000, Lille, France, chrystele.rubod@chru-lille.fr

e CHU Clermont-Ferrand, CHU Estaing, Pôle gynécologie obstétrique et reproduction humaine - Assistance médicale à la procréation - CECOS, Clermont-Ferrand, France, mcanis@chu-clermontferrand.fr 
$23{ }^{f}$ Department of Gynaecologic and Oncologic Surgery and Obstetrics, Centre Hospitalier

24 Universitaire Lyon Sud, Hospices Civils de Lyon, Université Lyon 1, France,

25 francois.golfier@chu-lyon.fr

26 g Department of Gyneacology and Obstetrics, CHI de Poissy St Germain en Laye, F-78303

27 Poissy, France Arnaud.Fauconnier@ght-yvelinesnord.fr

$28{ }^{\mathrm{h}}$ Endometriosis Center, Clinique Tivoli-Ducos, Bordeaux, France,

29 Horace.roman@gmail.com

30

31 Corresponding author: Charles-André PHILIP

32 - Address: Gynecology department, Croix-Rousse University Hospital, 103 Grande Rue de la

33 Croix-Rousse, 69004 Lyon, France.

34 - e-mail: charles-andre.philip@chu-lyon.fr

35 - phone number: +33472001564 
47 Word count of the text : 3000

\section{Highlights :} endometriosis lesions endometriosis;

\section{Word count of the abstract : 248} present study

- a series of 232 patients suffering from urinary tract endometriosis describing their symptoms and the most frequent locations.

- Ureteral endometriosis was significantly associated with other deep invasive

- Ureteral endometriosis was more often asymptomatic than bladder locations

Key Word : Bladder endometriosis-Diagnosis of urinary tract endometriosis-Ureteral

Ethical approval : after consulting independent ethics committee, no Institutional Review Board approval was required for this study.

Author Disclosure Statement: The authors report no conflict of interest related to the 


\section{ABSTRACT}

(247 Words)

Objective. To review prospectively the clinical characteristics of patients suffering from urinary tract endometriosis (UTE) in France, in 2017.

Study Design. We conducted a prospective observational multicenter study including women managed surgically for UTE in 31 French endometriosis expert centers (FRIENDS group) from January 1, 2017 to December 31, 2017. We distinguished patient with isolated bladder endometriosis ("IBE") or isolated ureteral endometriosis ("IUE") and patients associating both locations (mixed locations "ML"). Surgeons belonging to FRIENDS group enrolled patients by filling a 24 items questionnaire the day of the surgery and 6 weeks later. Data on the locations of UTE, preoperative assessment, urinary symptoms and associated pelvic locations were collected in a single anonymized database.

Results. A total of 232 patients from 31 centers were included. IBE concerned 82 patients (35.3\%), IUE 126 patients (54.4\%) ML 24 patients (10.3\%). 111 patients reported urinary symptoms (47.8\%). IUE was more often asymptomatic than the rest of the locations $(59.5 \%$ versus $43.3 \%$, OR 1,92, $p=0.017$ ). Associated deep infiltrating endometriosis (DIE) lesions were found in 193 patients (83.1\%). IUE was significantly associated with other DIE lesions (82.5\% versus $66 \%$, OR2.4, $p=0.006)$, particularly with rectum or sigmoid nodules $(57.1 \%$ versus $36.8 \%$, OR $2.3, p=0.002)$ and retrocervical space nodules $(31.7 \%$ versus $19.8 \%$, OR $1.9, p=0.05)$

Conclusion. Our study reports the second largest series of patients operated from a UTE and shows that ureteral location seems more frequent, less symptomatic and more frequently associated to other DIE locations than bladder endometriosis. 


\section{INTRODUCTION}

Deep infiltrating endometriosis (DIE) is defined as the infiltration by ectopic endometrial glands under the peritoneum for more than $5 \mathrm{~mm}$. The most frequent locations are the retrocervical space, uterosacral ligaments, the ovaries, the bowel wall and the urinary tracts $(1,2)$. Urinary tract endometriosis (UTE) is a rare location of the disease, which affects 1.2 to $6 \%$ of women (1-5). The incidence increase in populations of patients undergoing surgery for DIE (6). The bladder is usually reported as the most common location of UTE and may be present in up to $85 \%$ of cases $(22,37)$. The ureter is less often affected, with a prevalence ranging from 0.5 to $10 \%$ of UTE locations $(7,8)$. Bladder endometriosis $(\mathrm{BE})$ is responsible for symptoms of bladder irritation such as voiding dysfunction, polyuria, urgency, hematuria and urinary incontinence (9-15). Symptoms appear to be related to the location and size of the nodule (16).

The definition of ureteral endometriosis (UE) remains controversial. According to Nezhat et al., extrinsic and intrinsic form of UE endometriosis should be differentiated. Intrinsic endometriosis, which is defined by the involvement of the ureter wall may affect up to $20 \%$ of patients with UTE (17). Conversely, extrinsic UE is defined by an involvement of the ureter by an endometriosis nodule from adjacent structures(17). The incidence and characteristics of this pathology remains difficult to evaluate.

The objective of this study was to perform a prospective review of the main characteristics of patients with UTE in France during a one year period.. 


\section{MATERIAL AND METHOD}

\section{Population of the study}

We performed a multicentric prospective study on a population of patients managed surgically for deeply invasive UTE in France, from January 1, 2017 to December 31, 2017. All surgeons affiliated with the FRIENDS group (French coloRectal Infiltrating ENDometriosis Study group), were invited to prospectively and consecutively include all of their patients corresponding to the inclusions criteria, who underwent a surgery for UTE. The FRIEND group was founded in 2015 and consists of a network of advanced endometriosis surgeons in France. The aim was to foster shared experiences and collect routine data on surgery to improve DIE management between gynecologist surgeons interested in endometriosis (6).

In this study, patients were selected by their surgeon prior to surgery each time a surgical treatment for UTE was planned. Inclusion criteria were patients with suspected UTE who had at least one lesion of the bladder or ureter, regardless of if they were isolated or congruent with each other or congruent with another endometriotic lesion. Exclusion criteria included patients under age 18 and surgery limited to ureterolysis performed as part of the dissection for the resection of DIE or extra urinary endometriosis with absence of a bladder or ureteral lesion.

\section{Definition of UTE locations and surgeries}

We defined UTE as endometriosis involving the bladder, the ureter or both. BE (bladder endometriosis) was defined as a deep infiltration of the bladder including detrusor muscle, with or without mucosae infiltration according to Chapron et al. definition (18). Ureteral endometriosis (UE) was defined as any situation where there existed a compression or distortion of the ureter by ureteral endometriosis nodule, either with or without ureteral dilatation or hydronephrosis (17). Ureteral dilatation was defined as an abnormal ureteral diameter measured up to $4 \mathrm{~mm}$ in size (19). Hydronephrosis was defined as an abnormal renal pelvis measured up to $10 \mathrm{~mm}$ in size (19). Ureterolysis was defined as a dissection of the ureter from the endometriosis nodule until extracting all macroscopic endometriosis tissue and total liberation of the ureter, according to Nezhat et al and Uccella et al definition $(17,20)$. As 
explained previously, ureterolysis for the protection of the ureters prior to the resection of nodules not involving the bladder and ureters (DIE, uterosacral ligaments, rectal endometriosis, etc.) were excluded in this study.

\section{Population subgroups}

In our study, we distinguished five overlapping subgroups depending on the considered variable. Some analysis included nodules confined to one urinary location either bladder (isolated bladder endometriosis "IBE") or the ureters (isolated ureteral endometriosis "IUE"). In other part we considered all bladder lesions either associated or not with ureteral involvement (bladder endometriosis "BE") and all ureteral lesions either associated or not with a bladder involvement (ureteral endometriosis "UE"). A final subgroup including a combination of the mixed lesions (involving both ureter and bladder) was designated "mixed locations" (ML).

\section{Standardized questionnaire and data collection}

A 24-items questionnaire was sent to surgeons to be filled right after surgery. Patient demographic data were recorded (age at endometriosis diagnosis and surgery, parity, gravidity, history of surgery), as well as symptoms (urologic and non-urologic), pre-operative management (medical treatment, imaging examinations), location of urinary tract nodule or other locations of DIE, surgical procedure performed, and operative route. A specific part of the questionnaire concerned complications, which were defined as any adverse event in relation to the surgery, up to 6 weeks post operatively, according to the modified Clavien-Dindo classification (21). The questionnaires were anonymized and returned by surgeons at the end of the study period. Data were collected by a unique investigator (E.F.) in an anonymous database. Due to word constraints, data concerning surgical management and complication will be reported in a specific publication. 
150

The National Data Protection Authority (Commission Nationale de I'Informatique et des Liberte's) approved the study. All data were fully de-identified before analysis. Our work complied with French statutes and regulations, which authorize epidemiologic surveys without advance approval of an ethics committee. Our survey involved no intervention and is thus excluded from the French statute on biomedical research (Huriet-Serusclat law, dated December 20,1998). We complied with all French statutes concerning data about the subjects, confidentiality, and restrictions.

\section{Statistical analysis}

Data were collected in a Microsoft Excel for Windows files (Microsoft@, Redmond, Washington, USA). Median, mean, standard deviations were calculated directly in Microsoft Excel files. Odds ratios, relative risks, 95\% confidence intervals and all statistical analysis were performed using "R: A Language and Environment for Statistical Computing" (R Core Team $₫ 2008$ by the R Foundation for Statistical Computing Vienna, Austria). Univariate analysis: Wilcoxon rank sum test was used to look for association with continuous data. Fisher exact test was used to assess correlation and risk associated with binomial data. Data were considered significant if p-value was below $5 \%$. Each odds ratio and relative risk was calculated comparing the proportion of "positive" and "negative" value of each considered variable using the rest of our population of UTE patients as the reference population and not a whole endometriosis or healthy control population.

\section{RESULTS}

\section{Population and patient's characteristics}

A total of 232 patients with UTE were included in our study from January 1, 2017 to December 31, 2017. Among the members of the FRIENDS group, 31 centers participated in the study, $23(74.2 \%)$ were from University Hospitals and $8(25.8 \%)$ from private structures. The median number of inclusions by department was 5 and varied between 1 to 27 patients. 
175 Surgical history of endometriosis was reported in 76 patients (32.7\%) which involved a 176 urological location in 23 patients (9.9\%). The patients with IBE has a mean age of 32.6 years

177 (Standard Deviation $(S D)=5.56)$ against 34.4 years $(S D=7.05)$ for IUE $(p=0.08)$.

There was no significant difference for the mean age of first symptoms of urinary symptoms between IBE and IUE (30.7; SD 5.31 versus 31.4 SD 8.42 years, $p=0.46)$. The mean time between apparition of the first urinary symptoms and the diagnosis of UTE was 0.7 years (SD 1.46) for IBE and 1.1 years for IUE $(S D=5.84, p=0.63)$. There was no significant difference between IBE and IUE for the mean time between diagnosis of endometriosis and surgery (1.06 versus 1.68 years, respectively, $p=0.33$ ), neither for the mean time between the first urinary symptoms and surgery ( 1.75 versus 2.33 years respectively, $p=0.85)$. The existence of a preoperative ureteral dilatation or specific urinary symptoms did not influence the mean time between diagnosis and surgical management. Patients' characteristics were summarized in table 1

\section{Location of urinary lesions}

Among the 232 patients with UTE, 126 presented an IUE, 82 an IBE and 24 a ML. In total, 150 patients presented a ureteral involvement associated or not with a bladder involvement (Ureteral Endometriosis: UE), 134 were unilateral (89.3\%) and 16 were bilateral (10.6\%). Similarly, 106 patients (47.7\%) presented a bladder involvement associated or not with a ureteral involvement (Bladder Endometriosis: BE). Among BE lesions, 31 accounted for the bladder base (29.2\%), 70 the bladder dome (66\%), 8 the trigone $(7.5 \%)$ including 3 patients $(2.8 \%)$ which presented several bladder lesions (association of nodule of the bladder base and dome). (Table 1)

\section{Urinary symptoms}

Among the 232 patients, $111(47.8 \%)$ presented at least one urinary symptom. Fifty-one of them had IUE (45.9\%), 49 IBE (44.1\%) and $11 \mathrm{ML}$ (9.9\%). The urinary symptoms reported were voiding dysfunction (15.9\%), cystalgia $(21.1 \%)$, polyuria $(6.0 \%)$, urinary incontinence $(0.9 \%)$, urgency $(1.7 \%)$, macroscopic hematuria $(5.6 \%)$, and recurrent cystitis $(3.9 \%)$. The 
202

203

204

205

206

207

208

209

210

211

212

213

214

215

216

217

218

219

220

221

222

223

224

225

226

presence of cystalgia, polyuria and hematuria were more frequent in cases of IBE than in other locations $(46.3 \%$ versus $7.3 \%, \mathrm{OR}=10.9, \mathrm{p}<0.001,12.2 \%$ versus $2.6 \%, \mathrm{OR}=5.07, \mathrm{p}=0.007$, and $12.1 \%$ versus $2 \%, O R=6.81, p=0.002$ respectively).

IUE were more often asymptomatic than other locations $(59.5 \%$ versus 43.3 , OR $1.92, p$ $=0.017)$. However, the presence of lower back pain and renal colic were more frequent in IUE cases compared to other patients $(30.1 \%$ versus $6.6 \%$, OR $6.11, p<0.001$ and $4.8 \%$ versus $0 \%, \mathrm{OR}=+\infty, \mathrm{p}=0.03$ respectively) (Table 2 ).

IBE was significantly associated with the presence of cystalgia, polyuria and hematuria as compared to other locations (OR $10.9 \mathrm{p}<0.001$, OR 5.07, $\mathrm{p}=0.007$, and OR 6.18, $\mathrm{p}=0.002$ respectively). iUE was more frequent in asymptomatic patients (OR 1.92, $p=0.017$ ).

\section{Preoperative assessment}

Before surgery, 172 patients (74.1\%) underwent a pelvic MRI, $48(20.7 \%)$ a pelvic ultrasound, $58(25 \%)$ a CT scan and $50(21.5 \%)$ a cystoscopy. Nineteen renal scintigraphy $(8.1 \%)$ were performed (Table 1).

CT scan and renal scintigraphy were significantly associated to the presence of IUE (OR 2.05, $\mathrm{p}=0.02$ and $\mathrm{OR}+\infty, \mathrm{p}<0.001$ respectively), whereas a cystoscopy was significantly associated with the presence of IBE (OR 3.02, p<0.001). Among the patients presenting IUE, 12 underwent a preoperative cystoscopy, which was performed as part of the insertion of a Double-J stent (Table 2a, b). The existence of a hydronephrosis was significantly associated with the performance of a renal scintigraphy ( $O R=13.9, p<0.001)$.

\section{Associated pelvic locations}

One hundred and ninety three patients (83.1\%) presented at least one pelvic lesion associated with urological involvement. The most frequent associated locations were the digestive tract $(111,47.8 \%)$, the uterosacral ligaments $(95,40.9 \%)$, endometriomas $(60,25.7 \%)$ and the retrocervical space $(61,26.3 \%)$. 
227 IUE was significantly associated with the presence of other pelvic lesions, compared to the

228 rest of the urological locations $(82.5 \%$ versus $66 \%$, OR $2.4, p=0.006)$ and in particular with Gastrointestinal nodules (57.1\% versus $36.8 \%$, OR 2.3, $p=0.002)$ and retrocervical space nodules $(31.7 \%$ versus $19.8 \%$, OR $1.9, p=0.05)$. IUE and $M L$ were not significantly associated with other pelvic locations (Table 2 and 3 ).

Data regarding to ureteral dilatations and hydronephrosis were available for 164 patients (70.6\%) and 144 patients (62\%) respectively. Among them, a preoperative ureteral dilatation was reported in 68 patients (41.4\%) whereas a hydronephrosis was present in 20 patients (13.9\%).Ureteral dilatation or hydronephrosis were more commonly found in iUE cases compared to the rest of the locations (respectively $57.1 \%$ versus $18.1 \%$, OR 6.0 and $17.8 \%$ versus $5.7 \%, \mathrm{OR}=3.6)$. Four isolated bladder lesions were however associated with a ureteral dilatation and affected the bladder base in one case, the trigone in one case and the bladder dome in two cases.

The insertion of a Double-J Stent before or during surgery was reported in 107 patients (46\%) and concerned 66 patients with IUE (52.4\%), 22 patients with IBE (26.8\%) and 19 patients with ML (79.1\%). It was significantly associated with the presence of a ureteral lesion whether it was isolated $(52.4 \%$ for IUE versus $39.2 \%$ for $\mathrm{BE}, \mathrm{OR}=1.74, \mathrm{p}<0.04)$ or associated with bladder lesion (79.1\% for UE versus $22.6 \%$ for IBE, OR $=3.57 \mathrm{p}<0.001)$ (Table 2 and 3 ).

\section{DISCUSSION}

We report the results of a prospective longitudinal study, which included 232 patients managed surgically for UTE, in 31 French endometriosis center throughout the year 2017. To our knowledge, this is the second largest documented series of patients with UTE. Indeed, Ceccaroni et al recently reported a single center experience on 160 patients with UE and 264 patients with BE over a 10 years period $(21,22)$. 
252

We report 82 patients (35.3\%) with IBE, 126 (54.5\%) with IUE and 24 (10.3\%) with ML, accounting for a total of 150 ureteral lesions (UE) and a total of 106 bladder lesions (BE). The incidence of UTE in our series varied from $8 \%$ to $27.7 \%$ depending on the center. According to Nezhat et al., UTE concerns from $1 \%$ to $6 \%$ of patients suffering from endometriosis (17). In the series of Gabriel et al., the prevalence of UTE was to $19.5 \%$ and up to $52.6 \%$ in the series of Knabben et al. $(10,11)$.

We observed a higher rate of ureteral lesions than bladder lesions in this series $(64.6 \%$ for UE versus $45.7 \%$ for $B E$, ratio $=1.41$ ), while Macaggnanno et al. reported in their review a $85 \%$ rate of bladder lesions versus $9 \%$ of ureteral lesions (7). However, our results are consistent with those of Knabben et al., which reported a higher rate of ureteral lesions $(94.6 \%)$ than bladder lesions (14.3\%) (11). This variation in UTE repartition could be related to the existence of different definitions in UE and BE in the literature. Indeed, some authors only consider intrinsic nodule as real UE, which is defined by Nezhat et al. as an infiltration of ureteral wall by an endometriotic nodule. Conversely, Nezhat et al. also describe an extrinsic UE, which correspond to a compression or distortion of the pelvic ureter by a peritoneal nodule or an adjacent structure(17). In their study, Knabben et al. regrouped these two entities into UE definition (11). Similarly, we both included endometriosis nodule from the ureteral wall as well as compression of the ureter by an endometriosis nodule from an adjacent anatomical structure. However, by consensus with the whole FRIENDS group, ureterolysis performed as a prerequisite for resection of an endometrioma, a gastrointestinal nodule or utero sacral ligaments were excluded to avoid an overestimation of extrinsic ureteric involvement, which could be the case in some series (6). These distinctions raise the problem of the need for a common definition for UE, which is currently heterogenic in the literature. A new objective definition of UE could implicate pre-operative imaging.

We reported bilateral lesions in $10.7 \%$ of UTE patients, while ML accounted for 24 patients (10.3\%). These results are in agreement with the study of Cavaco-Gomez et al. which reported 
a rate of $10.6 \%$ bilateral UE and Chapron et al. which found a similar rate $(9.3 \%)$ of mixed urinary tract locations $(18,24)$.

We reported that UE was associated with less urinary symptoms than IBE $(41.3 \%$ versus $59,8 \%, R R=1.45, p=0.008$ ), while it was associated with "unspecific" endometriosis symptoms. Data from the literature confirm that UE remains asymptomatic in nearly $50 \%$ of the cases $(17,25)$. Cavaco-Gomez et al. reported also that UE was rarely associated with urinary symptoms (34.7\%) but frequently associated with unspecific symptoms (dysmenorrhea in $81.4 \%$ of cases, pelvic pain in $70.2 \%$ of cases and dyspareunia in $66.4 \%$ of cases). These findings can be justified by the high association between UE and other DIE locations, which could explain these unspecific symptoms.(24). In our series, lower back pain was much more frequent in IUE or UE than for the rest of the population $(30.1 \%, R R=4.57, p<0.001$ and 26.7 , $R R=4.35, p<0.001$ respectively). History of repetitive renal colics was only found in 6 cases of IUE $(4.8 \%, p=0.03)$. This association between lower back pain as also been reported in the literature, by Bosev et al. (11\% of patients) and by Frenna et al. $(9.2 \%$ of patients) $(26,27)$.

Conversely, we report that BE is significantly associated with numerous urinary symptoms. This association was also reported by Fauconnier et al. in 2002, confirming the high specificity of urinary symptoms for the diagnosis of BE (9). In a series assessing urinary symptoms in patients with posterior DIE isolated or associated with BE, Panel et al. also reported an association between the existence of cystalgia and the presence of BE (90\% versus $45 \%$, $p=0.024$ ) (14). Villa et al. also confirmed that location (bladder base) and size of BE lesion were related to the presence of this symptom (16).

In our study, $83 \%$ of UTE patients also presented associated DIE lesions; in particular IUE was strongly associated with gastrointestinal endometriosis. This association had already been described in the first prospective study of the FRIENDS group carried out on 1135 patients undergoing surgery for rectal and sigmoid endometriosis, which reported $13.4 \%$ of associated ureteral lesions (6).Based on 18 studies regrouping 668 patients with UE, Cavaco Gomez et 
al. also found $58.8 \%$ of rectal lesions associated with UTE (24). In is monocentric study

305 Ceccaroni et al report associated bowel nodule in $53 \%$ of BE and in $75.6 \%$ in case of UE. (21, 22) We also reported that retrocervical space lesions and parametrium nodules were strongly associated with IUE. These data illustrate from our point of view the importance of systematically looking for UE in patients presenting a posterior DIE and especially in case of rectum or sigmoid involvement.

CONCLUSION

311 Our study describes the main clinical characteristic of urinary tract endometriosis patient in

312 France, in 31 gynecological surgical departments over a one-year period. Schematically, we 313 distinguished two different populations of patients with their own characteristics: Patients with

314 UE are usually slightly older, often asymptomatic and present more frequently associated 315 posterior DIE lesions. Conversely, BE is associated with specific urinary symptoms (polyuria, 316 cystalgia, voiding dysfunction, hematuria) and presents less often concomitant DIE lesions.

317 The FRIENDS group, which has twice shown its ability to organize national prospective 318 studies, should continue on its path to improve the understanding of the surgical management 319 of endometriosis. 
Acknowledgment:

The authors would like to thank the following member of the FRIENDS group, who also participated to the study : C. CHAPRON, T. HEBERT, S. DOUVIER, L. FILIPUZZI, P. DESCAMPS, A. WATRELOT, A. AGOSTINI, J. BLANCHOT, C.M. ROGER, L. FRIEDERICH, P. COLLINET, P. VON THEOBALD, A. LETOHIC, M. MIMOUNI, A. MEPHON, T. GAUTHIER, N. HABIB, A. HOST, B.COTTE, R. RAMANAH, G. TRIOPON, F. GUILIBERT, F. AFCHIN,C. HOCKE, E.LAROUZEE, B.DOUSSET, A.PIVANO, E.BEAUVILLE, and B.RESCH. We also thank Mrs. Isabelle CAIN for her help with English editing. 


\section{REFERENCES}

1. Chapron C, Fauconnier A, Vieira M, Barakat H, Dousset B, Pansini V, et al. Anatomical distribution of deeply infiltrating endometriosis: surgical implications and proposition for a classification. Hum Reprod. 2003 Jan 1;18(1):157-61.

2. Scioscia M, Bruni F, Ceccaroni M, Steinkasserer M, Stepniewska A, Minelli L. Distribution of endometriotic lesions in endometriosis stage IV supports the menstrual reflux theory and requires specific preoperative assessment and therapy. Acta Obstet Gynecol Scand. 2011 Feb;90(2):136-9.

3. Berlanda N, Vercellini P, Carmignani L, Aimi G, Amicarelli F, Fedele L. Ureteral and Vesical Endometriosis: Two Different Clinical Entities Sharing the Same Pathogenesis. Obstet Gynecol Surv. 2009 Dec;64(12):830-42.

4. Kołodziej A, Krajewski W, Dołowy Ł, Hirnle L. Urinary Tract Endometriosis. Urol J. 2015 Sep 4;12(4):2213-7.

5. Nezhat C, Paka C, Gomaa M, Schipper E. Silent Loss of Kidney Seconary to Ureteral Endometriosis. JSLS. 2012;16(3):451-5.

6. Roman H, FRIENDS group (French coloRectal Infiltrating ENDometriosis Study group). A national snapshot of the surgical management of deep infiltrating endometriosis of the rectum and colon in France in 2015: A multicenter series of 1135 cases. J Gynecol Obstet Hum Reprod. 2017 Feb;46(2):159-65.

7. Maccagnano C, Pellucchi F, Rocchini L, Ghezzi M, Scattoni V, Montorsi F, et al. Diagnosis and treatment of bladder endometriosis: state of the art. Urol Int. 2012;89(3):249-58.

8. Yohannes P. Ureteral Endometriosis. J Urol. 2003 Jul;170(1):20-5. 
9. Fauconnier A, Chapron C, Dubuisson J-B, Vieira M, Dousset B, Bréart G. Relation between pain symptoms and the anatomic location of deep infiltrating endometriosis. Fertil Steril. 2002 Oct;78(4):719-26.

10. Gabriel B, Nassif J, Trompoukis P, Barata S, Wattiez A. Prevalence and Management of Urinary Tract Endometriosis. Urology. 2011 Dec;78(6):1269-74.

11. Knabben L, Imboden S, Fellmann B, Nirgianakis K, Kuhn A, Mueller MD. Urinary tract endometriosis in patients with deep infiltrating endometriosis: prevalence, symptoms, management, and proposal for a new clinical classification. Fertil Steril. 2015 Jan;103(1):14752.

12. Kumar S, Tiwari P, Sharma P, Goel A, Singh J, Vijay M, et al. Urinary tract endometriosis: Review of 19 cases. Urol Ann. 2012;4(1):6.

13. Leone Roberti Maggiore U, Ferrero S, Salvatore S. Urinary incontinence and bladder endometriosis: conservative management. Int Urogynecology J. 2015 Jan;26(1):159-62.

14. Panel P, Huchon C, Estrade-Huchon S, Le Tohic A, Fritel X, Fauconnier A. Bladder symptoms and urodynamic observations of patients with endometriosis confirmed by laparoscopy. Int Urogynecology J. 2016 Mar;27(3):445-51.

15. Vercellini P, Frontino G, Pietropaolo G, Gattei U, Daguati R, Crosignani PG. Deep endometriosis: definition, pathogenesis, and clinical management. J Am Assoc Gynecol Laparosc. 2004 May;11(2):153-61.

16. Villa G, Mabrouk M, Guerrini M, Mignemi G, Montanari G, Fabbri E, et al. Relationship between site and size of bladder endometriotic nodules and severity of dysuria. J Minim Invasive Gynecol. 2007 Sep;14(5):628-32. 
17. Nezhat C, Falik R, McKinney S, King LP. Pathophysiology and management of urinary tract endometriosis. Nat Rev Urol. 2017 May 3;14(6):359-72.

18. Chapron C, Bourret A, Chopin N, Dousset B, Leconte M, Amsellem-Ouazana D, et al. Surgery for bladder endometriosis: long-term results and concomitant management of associated posterior deep lesions. Hum Reprod. 2010 Apr 1;25(4):884-9.

19. Potenta SE, D'Agostino R, Sternberg KM, Tatsumi K, Perusse K. CT Urography for Evaluation of the Ureter. Radiogr Rev Publ Radiol Soc N Am Inc. 2015 Jun;35(3):709-26.

20. Uccella S, Cromi A, Casarin J, Bogani G, Pinelli C, Serati M, et al. Laparoscopy for ureteral endometriosis: surgical details, long-term follow-up, and fertility outcomes. Fertil Steril. 2014 Jul;102(1):160-166.e2.

21. Dindo D, Demartines N, Clavien P-A. Classification of Surgical Complications: A New Proposal With Evaluation in a Cohort of 6336 Patients and Results of a Survey. Ann Surg. 2004 Aug;240(2):205-13.

22. Ceccaroni M, Clarizia R, Ceccarello M, De Mitri P, Roviglione G, Mautone D, et al. Total laparoscopic bladder resection in the management of deep endometriosis: "take it or leave it." Radicality versus persistence. Int Urogynecology J. 2019 Sep 7;

23. Ceccaroni M, Ceccarello M, Caleffi G, Clarizia R, Scarperi S, Pastorello M, et al. Total Laparoscopic Ureteroneocystostomy for Ureteral Endometriosis: A Single-Center Experience of 160 Consecutive Patients. J Minim Invasive Gynecol. 2019;26(1):78-86.

24. Cavaco-Gomes J, Martinho M, Gilabert-Aguilar J, Gilabert-Estélles J. Laparoscopic management of ureteral endometriosis: A systematic review. Eur J Obstet Gynecol Reprod Biol. 2017 Mar;210:94-101. 
25. Seracchioli R, Mabrouk M, Manuzzi L, Guerrini M, Villa G, Montanari G, et al. Importance of retroperitoneal ureteric evaluation in cases of deep infiltrating endometriosis. J Minim Invasive Gynecol. 2008 Aug;15(4):435-9.

26. Bosev D, Nicoll LM, Bhagan L, Lemyre M, Payne CK, Gill H, et al. Laparoscopic Management of Ureteral Endometriosis: The Stanford University Hospital Experience With 96 Consecutive Cases. J Urol. 2009 Dec;182(6):2748-52.

27. Frenna V, Santos L, Ohana E, Bailey C, Wattiez A. Laparoscopic management of ureteral endometriosis: Our experience. J Minim Invasive Gynecol. 2007 Mar;14(2):169-71. 


\begin{tabular}{|c|c|c|c|c|c|c|c|}
\hline \multirow[b]{2}{*}{ Variable } & \multirow[b]{2}{*}{$\mathrm{N}=$} & \multicolumn{3}{|c|}{ Bladder endometriosis ${ }^{a}(82)$} & \multicolumn{3}{|c|}{ Ureteral endometriosis ${ }^{b}(126)$} \\
\hline & & YES * & OR & $p$-value & YES * & OR & $p$-value \\
\hline Surgical history for endometriosis & 76 & $16(19.5)$ & $\underline{0.36}$ & 0.001 & $53(42.4)$ & 2.78 & 0,001 \\
\hline \multicolumn{8}{|l|}{ Urinary symptoms } \\
\hline Asymptomatic patients & 121 & $33(40.2)$ & $\underline{0.47}$ & 0.008 & 75(59.5) & 1.92 & 0,017 \\
\hline Lower back pain & 45 & $5(6.1)$ & $\underline{0.18}$ & $<0.001$ & $38(30.1)$ & 6.11 & $<0,001$ \\
\hline Cystalgia & 49 & $38(46.3)$ & 10.9 & $<0.001$ & $5(4)$ & $\underline{0.06}$ & $<0,001$ \\
\hline Dysuria & 37 & $17(20.7)$ & 1.7 & 0.18 & 13(10.3) & $\underline{0.39}$ & 0,012 \\
\hline Polyuria & 14 & $10(12.2)$ & 5.07 & 0.007 & $4(3.2)$ & $\underline{0.31}$ & 0,05 \\
\hline Hematuria & 13 & $10(12.1)$ & 6.81 & 0.002 & $1(0.8)$ & $\underline{0.06}$ & $<0,001$ \\
\hline Recurrent cystitis & 9 & $6(7.3)$ & 3.87 & 0.07 & $1(0.8)$ & $\underline{0.09}$ & 0,01 \\
\hline Renal colics & 6 & $0(0)$ & 0 & 0.09 & $6(4.8)$ & $+\infty$ & 0,03 \\
\hline \multicolumn{8}{|l|}{ Preoperative imaging } \\
\hline $\mathrm{CT}$ & 58 & $9(10.1)$ & $\underline{0.25}$ & $<0.001$ & $39(31)$ & 2.05 & 0.02 \\
\hline MRI & 172 & $64(78)$ & 1.38 & 0.34 & $95(75.4)$ & 1.15 & 0.65 \\
\hline Pelvic or urinary ultrasound & 48 & $16(19.5)$ & 0.89 & 0.86 & $29(23)$ & 1.36 & 0.41 \\
\hline Cystoscopy & 40 & $28(34.1)$ & 3.02 & $<0.001$ & $12(9.5)$ & $\underline{0.19}$ & $<0.001$ \\
\hline Renal scintigraphy & 19 & $0(0)$ & $\underline{0}$ & $<0.001$ & 18(14. 3) & $+\infty$ & $<0.001$ \\
\hline \multicolumn{8}{|l|}{ High urinary tract dilatation } \\
\hline Ureteral dilatation & 68 & $4(8.2)$ & $\underline{0.07}$ & $<0.001$ & $56(57.1)$ & 6.0 & $<0.001$ \\
\hline Hydronephrosis & 19 & $0(0)$ & $\underline{0}$ & 0.001 & $16(17.8)$ & 3.60 & 0.04 \\
\hline \multicolumn{8}{|l|}{ Associated lesions } \\
\hline Digestive tract & 111 & $26(31.7)$ & $\underline{0.35}$ & $<0.001$ & 72(57.1) & 2.29 & 0,002 \\
\hline Adenomyosis & 19 & $4(4.9)$ & 0.46 & 0.21 & $14(0.11)$ & 2.52 & 0,08 \\
\hline Parametrium & 27 & $4(4.9)$ & $\underline{0.28}$ & 0.018 & 23(18.2) & 5.69 & $<0,001$ \\
\hline USL & 95 & $31(37.8)$ & 0.82 & 0.48 & $56(44.4)$ & 1.37 & 0,28 \\
\hline Endometrioma & 60 & $14(17.1)$ & $\underline{0.46}$ & 0.02 & $39(31)$ & 1.81 & 0,07 \\
\hline Retrocervical space & 61 & $15(18.3)$ & $\underline{0.51}$ & 0.04 & $40(31.7)$ & 1.88 & 0,05 \\
\hline \multicolumn{8}{|l|}{ Operative route } \\
\hline Laparoscopy & 169 & $62(75.6)$ & 1.24 & 0.54 & $93(73.8)$ & 1.11 & 0,76 \\
\hline Laparotomy (total) & 25 & $6(7.6)$ & 0.54 & 0.27 & $12(9.5)$ & 0.75 & 0.53 \\
\hline Laparoconversion & 8 & $3(3.7)$ & 1.1 & 1 & $1(0.8)$ & $\underline{0.11}$ & 0.02 \\
\hline \multicolumn{8}{|l|}{ Urological surgery } \\
\hline Double-J Stent & 107 & $22(26.8)$ & $\underline{0.28}$ & $<0.001$ & $66(52.4)$ & 1.74 & 0.04 \\
\hline Collaboration with urologist & 85 & $24(29.3)$ & 0.60 & 0.08 & $46(36.8)$ & 1 & 1 \\
\hline Ureteral resection & 28 & $0(0)$ & $\underline{0}$ & $<0.001$ & 24(19) & 6.00 & $<.001$ \\
\hline Ureteroneocystostomy & 23 & $0(0)$ & $\underline{0}$ & $<0.001$ & 20(15.9) & 6.48 & $<0.001$ \\
\hline Ureteroureterostomy & 5 & $0(0)$ & 0 & 0,16 & $4(3.2)$ & 3.44 & 0.38 \\
\hline Ureterolysis & 128 & $14(17.1)$ & $\underline{0.07}$ & $<0.001$ & $95(75,4)$ & 6.78 & $<0.001$ \\
\hline Partial cystectomy & 100 & 77(93.9) & $\underline{85.0}$ & $<0.001$ & $0(0)$ & 0 & $<0.001$ \\
\hline \multicolumn{8}{|l|}{ Associated surgical procedure } \\
\hline Retrocervical space & 64 & $15(18.3)$ & $\underline{0.46}$ & 0.02 & $41(32.5)$ & 1.74 & 0,07 \\
\hline Digestive tract & 109 & $25(30.1)$ & $\underline{0.34}$ & $<0.001$ & 72(57.1) & 2.48 & $<0,001$ \\
\hline Unilateral ovariectomy & 21 & $2(2.4)$ & $\overline{0.17}$ & 0.008 & $16(12,7)$ & 2.94 & 0,039 \\
\hline Bilateral ovariectomy & 14 & $1(1.2)$ & $\underline{0.13}$ & 0.02 & $9(7.1)$ & 1.55 & 0.44 \\
\hline Hysterectomy & 40 & $6(7.3)$ & $\underline{0.27}$ & 0.003 & $30(23,8)$ & 3.00 & 0,004 \\
\hline Parametrium nodules & 24 & $3(3.7)$ & $\underline{0.23}$ & 0.01 & $21(16.7)$ & 6.87 & $<0,001$ \\
\hline Uterine adenomyosis & 3 & $3(3.7)$ & $\overline{+\infty}$ & 0.04 & $0(0)$ & $\underline{0}$ & 0,09 \\
\hline \multicolumn{8}{|l|}{ Complications } \\
\hline Total & 61 & $17(20.7)$ & 0.63 & 0.16 & $35(27.8)$ & 1.18 & 0,65 \\
\hline Urological & 34 & $11(13.4)$ & 0.77 & 0.57 & $18(14.3)$ & 0.81 & 0,58 \\
\hline Second surgery & 14 & $4(4.9)$ & 0.72 & 0.77 & $9(7.1)$ & 1.55 & 0,58 \\
\hline
\end{tabular}




\begin{tabular}{|c|c|c|c|c|}
\hline \multirow[b]{2}{*}{ Variable } & \multirow[b]{2}{*}{$\mathrm{n}$} & \multicolumn{3}{|c|}{ Mixed Urinary Endometriosis c (24) } \\
\hline & & YES * & $O R$ & $p$-value \\
\hline Surgical history for endometriosis & 76 & $7(29.1)$ & 0.82 & 0.84 \\
\hline \multicolumn{5}{|l|}{ Urinary symptoms } \\
\hline Symptomatic patients & 111 & $11(45.8)$ & 0.91 & 1 \\
\hline Lower back pain & 45 & $2(8.3)$ & 0.34 & 0.18 \\
\hline Cystalgia & 49 & $6(25)$ & 1.27 & 0.60 \\
\hline Dysuria & 37 & $7(29.2)$ & 2.44 & 0.07 \\
\hline Polyuria & 14 & $0(0)$ & - & 0.37 \\
\hline Hematuria & 13 & $2(8.3)$ & 1.62 & 0.54 \\
\hline Recurrent cystitis & 9 & $2(8.3)$ & & 0.23 \\
\hline Renal colic & 6 & $0(0)$ & - & 1 \\
\hline \multicolumn{5}{|l|}{ Preoperative imaging } \\
\hline CT scan & 58 & $10(41.7)$ & 2.38 & 0.07 \\
\hline MRI & 172 & $13(54.2)$ & 0.36 & 0.02 \\
\hline Pelvic or urinary ultrasound & 48 & $3(12.5)$ & 0.51 & 0.43 \\
\hline Cystoscopy & 40 & $10(41.7)$ & 3.0 & 0.01 \\
\hline Renal scintigraphy & 19 & $1(4.2)$ & 0.46 & 0.70 \\
\hline \multicolumn{5}{|l|}{ High urinary tract dilatation } \\
\hline Ureteral dilatation & 68 & $8(47)$ & 1.29 & 0.62 \\
\hline Hydronephrosis & 19 & $3(23.1)$ & 2.14 & 0.38 \\
\hline \multicolumn{5}{|l|}{ Associated lesions } \\
\hline Digestive tract & 111 & $13(54.1)$ & 1.33 & 0.53 \\
\hline Adenomyosis & 19 & $1(4.2)$ & 0.45 & 0.70 \\
\hline Parametrium & 27 & $0(0)$ & 0 & 0.09 \\
\hline USL & 95 & $8(33.3)$ & 0.69 & 0.51 \\
\hline Endometrioma & 60 & $7(29.2)$ & 1.20 & 0.80 \\
\hline Retrocervical space & 61 & $6(25)$ & 0.92 & 1 \\
\hline \multicolumn{5}{|l|}{ Operative route } \\
\hline Laparoscopy & 169 & $14(58.3)$ & 0.47 & 0.14 \\
\hline Laparotomy (total) & 25 & $7(29.2)$ & 4.34 & 0.007 \\
\hline Laparoconversion & 8 & $4(16.7)$ & 10.2 & 0.005 \\
\hline \multicolumn{5}{|l|}{ Urological surgery } \\
\hline Double-J stent & 107 & 19(79.1) & 5.18 & $<0.001$ \\
\hline Association with urologist & 85 & $15(62.5)$ & 3.26 & $<0.001$ \\
\hline Ureteral resection & 28 & $4(16.7)$ & 1.53 & 0.50 \\
\hline Ureteroneocystostomy & 23 & $3(12.5)$ & 1.34 & 0.71 \\
\hline Ureteroureterostomy & 5 & $1(4.2)$ & 2.21 & 0.42 \\
\hline Ureterolysis & 128 & 19(79.2) & 3.45 & 0.02 \\
\hline Partial cystectomy & 100 & $23(95.8)$ & 39.1 & $<0.001$ \\
\hline \multicolumn{5}{|l|}{ Associated surgical procedure } \\
\hline Retrocervical space & 64 & $8(34.8)$ & 1.36 & 0.48 \\
\hline Digestive & 109 & $12(50)$ & 1.14 & 0.83 \\
\hline Unilateral ovariectomy & 21 & $3(12.5)$ & 1.5 & 0.46 \\
\hline Bilateral ovariectomy & 14 & $4(16.7)$ & 3.96 & 0.04 \\
\hline Hysterectomy & 40 & $4(16.7)$ & 0.96 & 1 \\
\hline Parametrium nodules & 24 & $0(0)$ & 0 & 0.15 \\
\hline Uterine adenomyosis & 3 & $0(0)$ & 0 & 1 \\
\hline \multicolumn{5}{|l|}{ Complications } \\
\hline Total & 61 & $9(37.5)$ & 1.8 & 0.22 \\
\hline Urological & 34 & $7(29.1)$ & 2.54 & 0.07 \\
\hline Second surgery & 14 & $1(4.2)$ & 0.65 & 0.20 \\
\hline $\begin{array}{l}\text { Notes: } R R=\text { relative risk of presenting } \\
(N O) \text { of a mixed location }(M L) \text {. USL: } U t \\
\text { mixed locations }(M L)(+) \text { and the rest }\end{array}$ & sacri & $\begin{array}{l}\text { accordin } \\
\text { ments * } \\
\text { location }\end{array}$ & the & $\begin{array}{l}\text { רce (YES) or not } \\
\text { yrison between }\end{array}$ \\
\hline
\end{tabular}

